Polymer Journal, Vol. 9, No. 5, pp 511-518 (1977)

\title{
Polymerization of $a, a$-Dimethylbenzyl Methacrylate and Its Copolymerization with Methyl Methacrylate by Anionic Initiators
}

\author{
Heimei Yuki, Koji Ohta, Koichi Hatada, and Yoshio Oкamoto \\ Department of Chemistry, Faculty of Engineering Science, \\ Osaka University, Toyonaka, Osaka 560, Japan.
}

(Received April 23, 1977)

\begin{abstract}
Dimethylbenzyl methacrylate (DMBMA) was polymerized by anionic initiators and the tacticities of the polymers were determined from the PMR spectra of poly(methyl methacrylate)s derived from them. By butyllithium ( $n$-BuLi), an isotactic polymer was obtained in toluene and a syndiotactic one in tetrahydrofuran (THF). Grignard reagents gave isotactic polymers in good yields. DMBMA was copolymerized with methyl methacrylate (MMA) by $n$-BuLi in toluene and THF. The copolymerization in toluene produced two kinds of copolymers: one was the usual copolymer, and the other predominantly consisted of MMA over $90 \%$ and was a mixture of isotactic and syndiotactic polymers. The stereoregularity of the copolymer obtained in THF was close to that of the homopolymer of DMBMA.

KEY WORDS Anionic Polymerization / Copolymerization / $\alpha, \alpha-$ Dimethylbenzyl Methacrylate / Methyl Methacrylate / Butyllithium / Grignard Reagents / Tacticity / Multiplicity of Active Species /
\end{abstract}

In the previous works, ${ }^{1-3}$ we studied the stereospecific polymerizations of various methacrylates, such as trityl (TrMA), diphenylethyl (DPEMA), diphenylmethyl (DPMMA), (R)- $\alpha$ methylbenzyl (MBMA) and benzyl (BzMA) methacrylates by anionic initiators. By butyllithium ( $n$-BuLi), MBMA and BzMA produced polymers having various tacticities according to the polymerization conditions, and the tacticities were similar to those of the poly(methyl methacrylate)s (PMMA) prepared under the same conditions. DPMMA gave exceptionally highly isotactic and syndiotactic polymers in toluene and in tetrahydrofuran (THF), respectively. TrMA gave a highly isotactic polymer in THF as well as in toluene. DPEMA yielded rather atactic polymers regardless of the polymerization medium. These characteristic features of methacrylates in anionic polymerization may be due to the bulkiness of the ester groups in these monomers. $\alpha, \alpha$-Dimethylbenzyl methacrylate (DMBMA) seems to lie between DPMMA and DPEMA in terms of the bulkiness of the ester group. This led us to investigate the polymerization of DMBMA and its copolymerization with other methacrylates.

\section{EXPERIMENTAL}

\section{Materials}

DMBMA was synthesized in ether from $\alpha, \alpha$ dimethylbenzyl alcohol ${ }^{4}$ and methacryloyl chloride in the presence of triethylamine under reflux for $24 \mathrm{hr}$. The crude product was fractionally distilled under reduced nitrogen pressure; bp $70^{\circ} \mathrm{C} / 0.4 \mathrm{mmHg}$. $n_{\mathrm{D}}^{30} 1.5020$. Anal. Found: C, 76.57; $\mathrm{H}, 7.85$. Calcd for $\mathrm{C}_{13} \mathrm{H}_{16} \mathrm{O}_{2}$ : C, 76.44; $\mathrm{H}, 7.90$.

MMA was purified in the usual manner, dried over a mixture of molecular sieves type $4 \mathrm{~A}$ and $\mathrm{CaH}_{2}$, and distilled in vacuo. It was redistilled over $\mathrm{CaH}_{2}$ under high vacuum just before use.

$n$-BuLi was prepared in heptane or toluene according to Ziegler's method ${ }^{5}$ from butyl chloride and metallic lithium under an argon atmosphere. 
Grignard Reagents. Phenyl-, cyclohexyl-, and isobutylmagnesium bromide $(\mathrm{PhMgBr}, \mathrm{CyMgBr}$, and $\mathrm{IBMgBr}$, respectively) were prepared in ether. The ether was replaced with toluene by distillation under reduced nitrogen pressure at room temperature. The procedure was repeated three times. The content of the residual ether in the solution was analyzed from the PMR spectrum of volatile materials distilled from the reaction mixture of the solution and water at $0^{\circ} \mathrm{C}$. The intensity measurement was made by a coaxial tubing method. ${ }^{6}$ The amounts of residual ether were $0.4-0.8 \mathrm{~mol}$ per mole of the $\mathrm{Mg}$ compounds.

The solutions of diphenylaminomagnesium bromide $\left(\mathrm{Ph}_{2} \mathrm{NMgBr}\right)$ and pentamethyleniminomagnesium bromide $\left[\left(\mathrm{CH}_{2}\right)_{5} \mathrm{NMgBr}\right]$ were obtained by reactions of $\mathrm{PhMgBr}$ in toluene with an equimolar amount of diphenylamine and piperidine, respectively, at room temperature. The reaction of $\mathrm{PhMgBr}$ and piperidine in toluene- $d_{8}$ was followed by PMR spectroscopy, and was found to go to completion within $5 \mathrm{~min}$.

Lithium diphenylamide $\left(\mathrm{Ph}_{2} \mathrm{NLi}\right)$ was prepared from diphenylamine and $n$-BuLi in toluene at room temperature. ${ }^{7}$

Diethylaluminum diphenylamide $\left(\mathrm{Et}_{2} \mathrm{AlNPh}_{2}\right)$ was prepared from triethylaluminum and $\mathrm{di}$ phenylamine at $90^{\circ} \mathrm{C}$ in toluene. ${ }^{7,8}$

Toluene purified in the usual manner was stored over metallic sodium. Before being used, it was mixed with a small amount of $n$-BuLi in toluene and redistilled under high vacuum.

THF was refluxed over $\mathrm{CaH}_{2}$ under a nitrogen atmosphere. It was redistilled over $\mathrm{LiAlH}_{4}$ in vacuo just before use.

Nitrogen was purified by passing it through a column packed with molecular sieves of the type $4 \mathrm{~A}$, cooled to $-78^{\circ} \mathrm{C}$.

\section{Polymerization}

A glass ampoule equipped with a three-way stopcock was dried by flame while being evacuated, and was filled with dry nitrogen. The monomer and solvent were introduced into the ampoule with hypodermic syringes. The polymerization was initiated by adding a catalyst to the monomer solution at a given temperature. The reaction was brought to a stop by adding a small amount of methanol, and the polymer was precipitated by pouring the reaction mixture into a large amount of methanol. After standing overnight, the polymer was collected by filtration, washed several times with methanol, and dried in vacuo at $60^{\circ} \mathrm{C}$.

Conversion of Dimethylbenzyl Ester in the Polymer to Methyl Ester

The ester group in poly(DMBMA) was quantitatively hydrolyzed by refluxing it in methanol containing $0.5 \%$ of concentrated hydrochloric acid for $6 \mathrm{hr}$. The poly(methacrylic acid) (PMAA) thus obtained was methylated with diazomethane in benzene. ${ }^{9}$ The DMBMA units in the copolymer of MMA and DMBMA were selectively hydrolyzed by the methanolic hydrochloric acid, and the poly(MMA-co-MAA) obtained was converted into PMMA by methylation.

\section{Measurements}

PMR spectra were measured with a JNMMH-100 spectrometer (JEOL) at $100 \mathrm{MHz}$. The spectra of PMMA and poly(MMA-co-DMBMA) were obtained at $60^{\circ} \mathrm{C}$ using tetramethylsilane (TMS) as an internal standard in $\mathrm{CDCl}_{3}$ and $\mathrm{CCl}_{4}$, respectively. The spectra of poly(MMAco-MAA) were taken for a 10- $\%$ solution in pyridine- $d_{5}$ using hexamethyldisiloxane (HMDS) as the internal reference at $100^{\circ} \mathrm{C}$.

Solution viscosity of the polymer was determined for a $0.5-\%$ solution in toluene at $30 \pm$ $0.02^{\circ} \mathrm{C}$ using an Ostwald-type viscometer.

\section{RESULTS}

\section{Tacticity Measurement of Poly $(D M B M A)$}

In Figure 1 is shown the PMR spectrum of poly(DMBMA) obtained by $n$-BuLi in toluene at $30^{\circ} \mathrm{C}$ together with that of the PMMA derived from it. Although splittings due to the configurational sequences in poly(DMBMA) were observed in the signal of its $\alpha$-methyl protons, the poor resolution makes it difficult to estimate the fractions of tactic triads from the signal. An attempt to improve the resolution of the spectrum by measuring it at an even higher temperature was not successful. So the tacticity was estimated from the spectrum of the PMMA derived.

\section{Polymerization of DMBMA}

The results of the polymerization of DMBMA 
Anionic Polymerization of Dimethylbenzyl Methacrylate

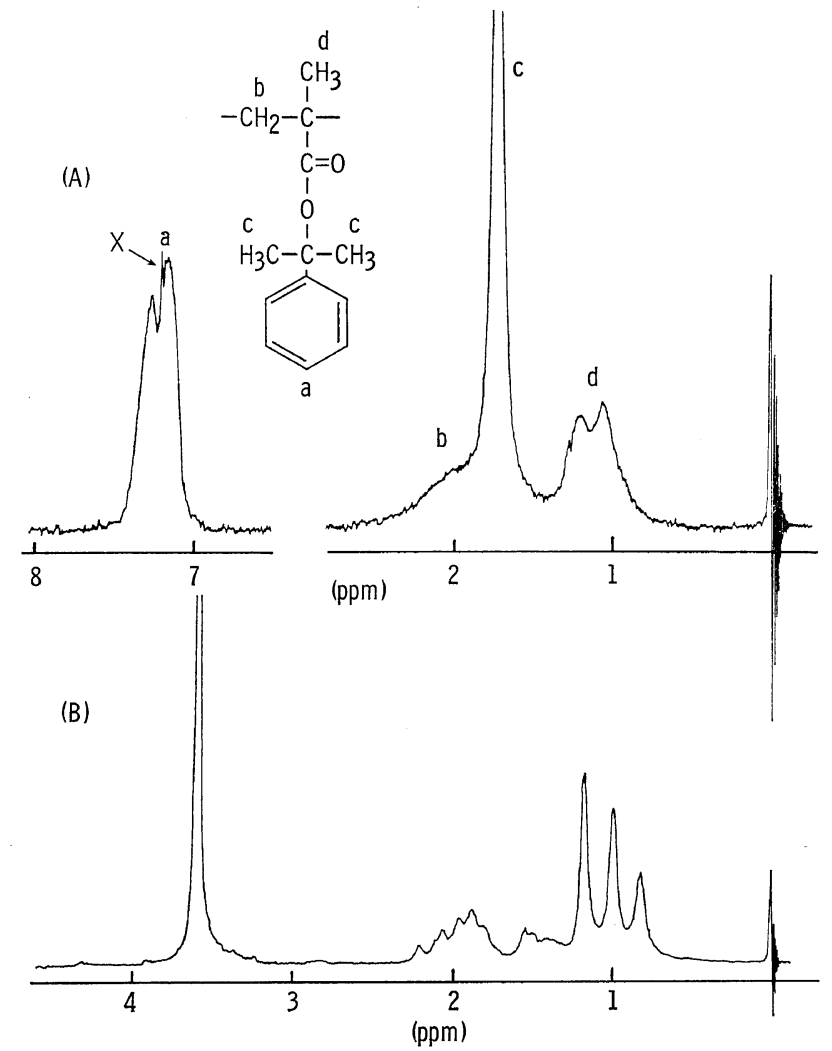

Figure 1. PMR spectra of (A) poly(DMBMA) and (B) PMMA in $\mathrm{CDCl}_{3}$ at $60^{\circ} \mathrm{C}$ : (A) obtained in toluene by $n$-BuLi at $30^{\circ} \mathrm{C}$; (B) derived from (A); $\mathrm{X}, \mathrm{CHCl}_{3}$ being contained in solvent.

Table I. Polymerization of DMBMA by $n$-BuLi ${ }^{\mathrm{a}}$

\begin{tabular}{|c|c|c|c|c|c|c|}
\hline \multirow{2}{*}{ Solvent } & \multirow{2}{*}{ Temp, } & \multirow{2}{*}{$\underset{\%}{\text { Yield, }}$} & \multirow{2}{*}{$\begin{array}{c}\eta_{\mathrm{sp}} / C \\
\mathrm{~d} l / \mathrm{g}\end{array}$} & \multicolumn{3}{|c|}{ Tacticity, \% } \\
\hline & & & & $I$ & $H$ & $S$ \\
\hline Toluene & -78 & 74 & 1.02 & 68 & 19 & 13 \\
\hline Toluene & -40 & 91 & 0.26 & 75 & 17 & 8 \\
\hline Toluene & 0 & 86 & 0.19 & 60 & 27 & 13 \\
\hline Toluene & 30 & 91 & 0.11 & 43 & 34 & 23 \\
\hline THF & -78 & 92 & 0.06 & 10 & 29 & 61 \\
\hline $\mathrm{THF}$ & -40 & 88 & 0.14 & 9 & 34 & 57 \\
\hline THF & 0 & 88 & 0.09 & 11 & 37 & 52 \\
\hline $\mathrm{THF}$ & 30 & 84 & 0.11 & 12 & 35 & 53 \\
\hline Toluene $^{b}$ & -78 & 90 & - & 38 & 22 & 40 \\
\hline Toluene ${ }^{b}$ & 0 & 99 & - & 47 & 32 & 21 \\
\hline
\end{tabular}

a Monomer, $5 \mathrm{mmol}$; solvent, $10 \mathrm{ml}$; $n$-BuLi, 0.25 mmol; time, $24 \mathrm{hr}$.

b Containing $1 \%$ of THF.
Table II. Polymerization of DMBMA in toluene by various initiators ${ }^{a}$

\begin{tabular}{|c|c|c|c|c|c|}
\hline \multirow{2}{*}{ Initiator } & \multirow{2}{*}{ Temp, } & \multirow{2}{*}{$\underset{\%}{\text { Yield, }}$} & \multicolumn{3}{|c|}{ Tacticity, \% } \\
\hline & & & $I$ & $H$ & $S$ \\
\hline PhMgBr & -78 & 95 & 92 & 5 & 3 \\
\hline $\mathrm{PhMgBr}$ & 0 & 78 & 90 & 7 & 3 \\
\hline $\mathrm{PhMgBr}$ & 30 & 87 & 74 & 16 & 10 \\
\hline CyMgBr & -78 & 9 & 33 & 22 & 45 \\
\hline CyMgBr & 0 & 88 & 86 & 9 & 5 \\
\hline IBMgBr & -78 & 63 & 67 & 12 & 21 \\
\hline IBMgBr & 0 & 89 & 72 & 19 & 9 \\
\hline $\mathrm{Ph}_{2} \mathrm{NMgBr}$ & 0 & 100 & 91 & 8 & 1 \\
\hline$\left(\mathrm{CH}_{2}\right)_{5} \mathrm{NMgBr}$ & 0 & 100 & 11 & 38 & 51 \\
\hline $\mathrm{Ph}_{2} \mathrm{NLi}$ & 0 & 98 & 49 & 31 & 20 \\
\hline $\mathrm{Et}_{2} \mathrm{AlNPh}_{2}{ }^{\mathrm{b}}$ & -78 & 97 & 1 & 17 & 82 \\
\hline AIBN & 60 & 66 & 11 & 47 & 42 \\
\hline
\end{tabular}

a Monomer, $5 \mathrm{mmol}$; toluene, $10 \mathrm{ml}$; initiator, $0.15-0.25 \mathrm{mmol}$; time, $24 \mathrm{hr}$.

b Time, $96 \mathrm{hr}$. 


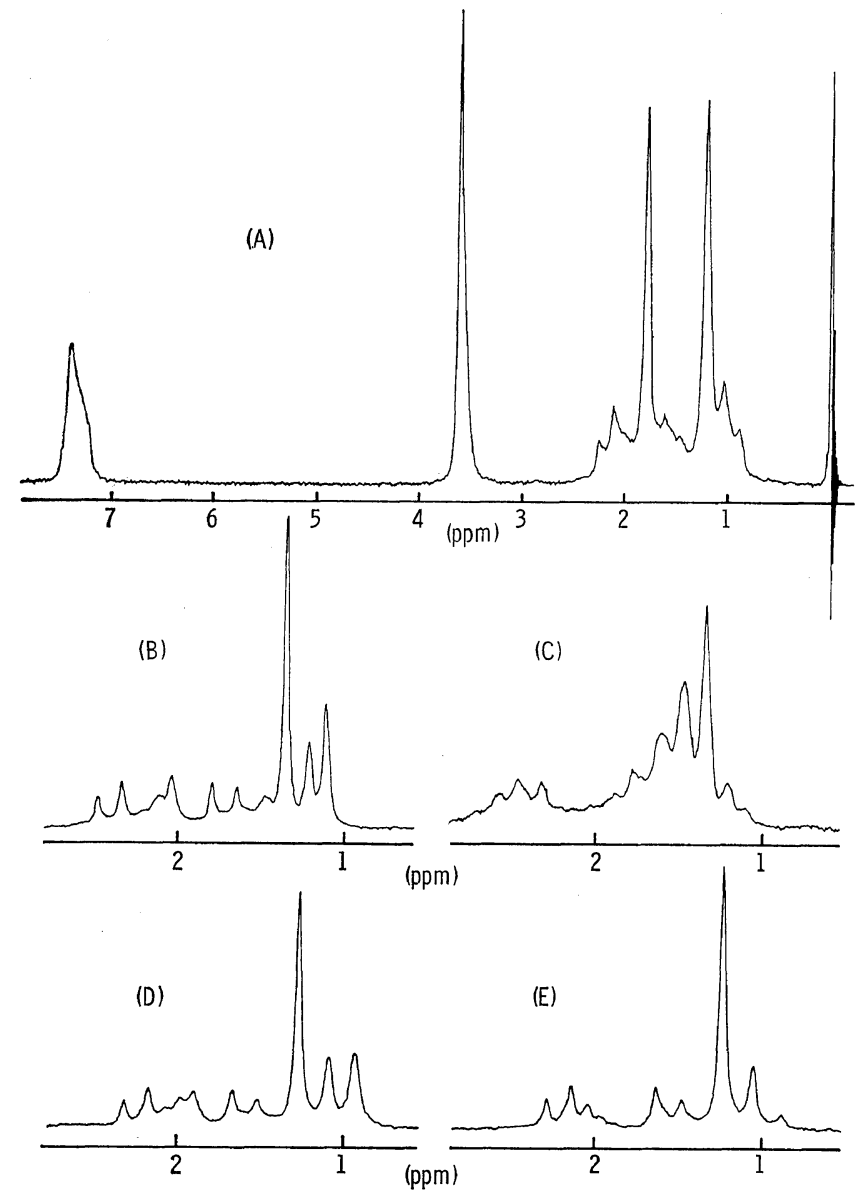

Figure 2. PMR spectra of poly(MMA-co-DMBMA), hydrolyzed copolymers and PMMAs: (A) poly(MMA-co-DMBMA) obtained in toluene by $n$-BuLi at $0^{\circ} \mathrm{C}\left(\mathrm{CCl}_{4}, \mathrm{TMS}, 60^{\circ} \mathrm{C}\right)$; (B) Part I obtained from A (pyridine- $d_{5}$, HMDS, $100^{\circ} \mathrm{C}$ ); (C) Part II obtained from A (pyridine- $d_{5}, \mathrm{HMDS}, 100^{\circ} \mathrm{C}$ ); (D) PMMA derived from B $\left(\mathrm{CDCl}_{3}\right.$, TMS, $\left.60^{\circ} \mathrm{C}\right)$; (E) PMMA derived from $\mathrm{C}\left(\mathrm{CDCl}_{3}, \mathrm{TMS}, 60^{\circ} \mathrm{C}\right)$.

by $n$-BuLi are shown in Table I. The polymers produced in toluene were isotactic, and the maximum isotacticity was obtained at $-40^{\circ} \mathrm{C}$. The polymerization in THF gave syndiotactic polymers, and the syndiotacticity decreased slightly at higher polymerization temperatures. The addition of 1-\% THF to the polymerization in toluene caused a decrease of isotacticity accompanied with an increased syndiotacticity, and the polymer obtained at $-78^{\circ} \mathrm{C}$, was found to be a mixture of isotactic and syndiotactic polymers by the thin-layer chromatogram of the PMMA derived from it. ${ }^{10}$
The results of the polymerizations of DMBMA by various initiators in toluene are shown in Table II. In general, Grignard reagents gave isotactic polymers in good yield. However, the degree of the stereoregularity of polymer and its temperature dependence were varied with the types of the Grignard reagents used.* A polymer rich in syndiotacticity was obtained by

* The polymer, which seems to be a stereo-blend type, was obtained by $\mathrm{CyMgBr}$ only in low yield at $-78^{\circ} \mathrm{C}$. However, it is not clear if there is any correlation or not between the tacticity and the yield of the polymer. 
Anionic Polymerization of Dimethylbenzyl Methacrylate

Table III. Copolymerization of MMA and DMBMA in toluene by $n-\mathrm{BuLi}^{\mathrm{a}}$

\begin{tabular}{|c|c|c|c|c|c|c|c|c|c|c|c|c|c|}
\hline \multirow{4}{*}{$\underset{{ }^{\circ} \mathrm{C}}{\text { Temp }}$} & \multirow{4}{*}{$\underset{\mathrm{hr}}{\text { Time, }}$} & \multirow{4}{*}{$\begin{array}{l}\text { Yield, } \\
\text { wt }{ }^{\circ}\end{array}$} & \multirow{4}{*}{$\begin{array}{c}\text { MMA } \\
\text { content, } \\
\text { mol\% }\end{array}$} & \multicolumn{10}{|c|}{ The hydrolyzed copolymer } \\
\hline & & & & \multicolumn{5}{|c|}{ Part I } & \multicolumn{5}{|c|}{ Part II } \\
\hline & & & & \multirow{2}{*}{$\begin{array}{l}\text { Yield, } \\
\text { wt } \%\end{array}$} & \multirow{2}{*}{$\begin{array}{l}\text { MMA } \\
\text { content, b } \\
\text { mol } \%\end{array}$} & \multicolumn{3}{|c|}{ Tacticity, $\%$} & \multirow{2}{*}{$\begin{array}{l}\text { Yield, } \\
\text { wt\% }\end{array}$} & \multirow{2}{*}{$\begin{array}{l}\text { MMA } \\
\text { content, } \\
\text { mol } \%\end{array}$} & \multicolumn{3}{|c|}{ Tacticity, $\%$} \\
\hline & & & & & & $I$ & $H$ & $S$ & & & $I$ & $H$ & $S$ \\
\hline-78 & 20 & 21 & 83 & 8 & 97 & 67 & 22 & 11 & 13 & 75 & 68 & 24 & 8 \\
\hline-40 & 2 & 32 & 73 & 4 & 93 & 46 & 28 & 26 & 28 & 60 & 70 & 23 & 7 \\
\hline 0 & 0.017 & 5 & 80 & 2 & 93 & 50 & 23 & 27 & 3 & 69 & 74 & 21 & 5 \\
\hline 0 & 0.033 & 14 & 73 & 4 & 90 & 56 & 20 & 24 & 10 & 68 & 73 & 22 & 5 \\
\hline 0 & 0.05 & 20 & 71 & $3^{c}$ & 90 & 54 & 21 & 25 & $17^{\mathrm{d}}$ & 66 & 74 & 21 & 5 \\
\hline 0 & 0.17 & 51 & 61 & 3 & 87 & 56 & 20 & 24 & 48 & 62 & 73 & 21 & 6 \\
\hline 0 & 0.50 & 66 & 52 & 4 & 79 & 57 & 20 & 23 & 62 & 56 & 72 & 22 & 6 \\
\hline 30 & 0.05 & 38 & 66 & 3 & 91 & 63 & 19 & 18 & 35 & 62 & 65 & 26 & 9 \\
\hline
\end{tabular}

a MMA, $10 \mathrm{mmol}$; DMBMA, $10 \mathrm{mmol}$; toluene, $40 \mathrm{ml}$; $n$-BuLi, $1.0 \mathrm{mmol}$.

b Determined by the intensity measurements of methoxyl proton resonance and methylene and $\alpha$ methyl ones.

$c, \mathbb{a}$ The molecular weight was calculated on the derived PMMA according to the equation $[\eta]=7.0 \times$ $10^{-5} \bar{M}_{v}^{0.71}:$ c, 190,$200 ; \mathrm{d}, 36,300$.

$\left(\mathrm{CH}_{2}\right)_{5} \mathrm{NMgBr}$. DMBMA gave a highly syndiotactic polymer by $\mathrm{Et}_{2} \mathrm{AlNPh}_{2}$ as also in the case of many other methacrylates. ${ }^{11}$ The radical polymerization by azobisisobutyronitrile (AIBN) gave a polymer rich in heterotacticity.

Copolymerization of MMA and DMBMA by $n-B u L i$

The copolymerization of equimolar amounts of MMA and DMBMA was carried out at various temperatures by $n-\mathrm{BuLi}$ in toluene. The composition of the copolymer was determined from the intensity ratio between the signals of the phenyl and methoxyl protons in the PMR spectrum of the copolymer (A in Figure 2). These results are shown in Table III. When the poly(MMA-co-DMBMA) was hydrolyzed in methanol- $\mathrm{HCl}$, the hydrolyzate, poly(MMAco-MAA), was separated into two portions: the first (Part I) insoluble and the second (Part II) soluble respectively in methanol (Table III). Spectra $\mathrm{B}$ and $\mathrm{C}$ in Figure 2 are respectively the methyl and methylene proton resonances of each fraction. The spectra indicate that Part I is composed mainly of MMA units, while Part II of a copolymer containing about the same amounts of both monomer units. The yield of Part I was small and decreased with a rise in the temperature of polymerization, but remained nearly constant at $0^{\circ} \mathrm{C}$ regardless of the time
Table IV. Copolymerization of MMA and DMBMA in THF by $n$-BuLi ${ }^{a}$

\begin{tabular}{rcccccc}
\hline \multirow{2}{*}{$\begin{array}{r}\text { Temp } \\
{ }^{\circ} \mathrm{C}\end{array}$} & $\begin{array}{r}\text { Yield, } \\
\text { wt\% }\end{array}$ & $\begin{array}{c}\text { MMA } \\
\text { content, } \\
\text { mol\% }\end{array}$ & \multicolumn{3}{c}{ Tacticity, $\%$} \\
\hline-78 & 88 & 54 & 7 & 31 & 62 \\
-40 & 80 & 46 & 10 & 33 & 57 \\
0 & 93 & 49 & 8 & 34 & 58 \\
30 & 10 & 44 & - & - & - \\
\hline
\end{tabular}

a MMA, $2.5 \mathrm{mmol}$; DMBMA, $2.5 \mathrm{mmol}$; THF, 10 $\mathrm{ml}$; $n$-BuLi, $0.25 \mathrm{mmol}$; time, $24 \mathrm{hr}$.

for polymerization. The intrinsic viscosities of the PMMAs derived from these portions indicated that the molecular weight of Part $I$ is much higher than that of Part II. The PMR spectra and tacticities of the PMMAs are shown in Figure 2 (D and E) and Table III, respectively. The isotacticity of Part I was lower than that of Part II, particularly for the polymers obtained at -40 and $0^{\circ} \mathrm{C}$. It was found from thin-layer chromatography $^{10}$ that Part $\mathrm{I}$, which originated from the copolymer prepared at $0^{\circ} \mathrm{C}$, was a mixture of isotactic and syndiotactic polymers, while Part II appeared to be rather homogeneous in stereoregularity.

The copolymerization of MMA and DMBMA in THF was also carried out by $n$-BuLi (Table IV). These copolymers are considered to be 
homogeneous, since all the hydrolyzates of the copolymers were soluble in methanol. The copolymer was predominantly syndiotactic and the tacticity was very similar to that of the homopolymer of DMBMA prepared in the same solvent.

\section{DISCUSSION}

\section{Polymerization of DMBMA}

In Table $\mathrm{V}$ the tacticity of poly(DMBMA) obtained by $n$-BuLi at $-78^{\circ} \mathrm{C}$ has been presented in comparison with the tacticities of other various polymethacrylates. ${ }^{1-3,11}$ The degree of isotacticity of the polymer prepared in toluene has the order: DPMMA $\cong$ TrMA $>$ DMBMA $>$ DPEMA among the polymers with bulky ester groups, while the order of syndiotacticity of the polymer prepared in THF is DPMMA> DMBMA $>$ DPEMA $>$ TrMA. Except for the isotacticity of TrMA, the stereoregularity (both isotacticity and syndiotacticity) of the polymer decreases with increase in the bulkiness of ester group in the monomeric unit. However, in spite of the bulky ester group, the stereospecific polymerization of DMBMA resembles to those of MMA, BzMA, and MBMA, in contrast with the unusual behavior of DPMMA, DPEMA, and TrMA in polymerization. It seems that more than two phenyl groups are necessary in the ester group of methacrylate to cause drastic change in the stereospecific polymerization by $n$-BuLi. The stereoregularity of various polymethacrylates prepared by $\mathrm{PhMgBr}$ in toluene at $30^{\circ} \mathrm{C}$ is summarized in Table VI. TrMA gave no polymer. DPMMA, which gave a highly isotactic polymer by $n-\mathrm{BuLi}$, produced a polymer with low stereoregularity by $\mathrm{PhMgBr}$, while DPEMA, which gave only an atactic polymer by the lithium initiator, yielded a polymer with high isotacticity by the Grignard reagent. The stereoregularity of poly(DMBMA) lies again between those of the poly(DPMMA) and the poly(DPEMA). The stereoregularity of the polymer changes not only with monomer methacrylate but also with the kind of Grignard reagent as shown in Table II, indicating that the Grignard reagent functions not just as an initiator in the initiation step of polymerization, but also affects the propagation step as a moiety of counter
Table V. Stereoregularity of polymethacrylates obtained by $n$-BuLi at $-78^{\circ} \mathrm{C}$ in toluene and THF

\begin{tabular}{|c|c|c|c|c|c|c|c|}
\hline \multirow{2}{*}{ Monomer } & \multicolumn{3}{|c|}{ in Toluene } & \multicolumn{3}{|c|}{ in $\mathrm{THF}$} & \multirow{2}{*}{ Reference } \\
\hline & $I$ & $H$ & $S$ & $I$ & $H$ & $S$ & \\
\hline MMA & 72 & 17 & 11 & 6 & 38 & 56 & 11 \\
\hline BzMA & 81 & 15 & 4 & 6 & 31 & 63 & 1 \\
\hline (R)-MBMA & 78 & 17 & 5 & 12 & 28 & 60 & 2 \\
\hline DPMMA & 99 & 1 & 0 & 2 & 11 & 87 & 1 \\
\hline DMBMA & 68 & 19 & 13 & 10 & 29 & 61 & This work \\
\hline DPEMA & 23 & 28 & 49 & 21 & 46 & 33 & 3 \\
\hline TrMA & 96 & 2 & 2 & 94 & 4 & 2 & 1 \\
\hline
\end{tabular}

Table VI. Stereoregularity of polymethacrylates obtained by $\mathrm{PhMgBr}$ in toluene at $30^{\circ} \mathrm{C}$

\begin{tabular}{|c|c|c|c|c|c|}
\hline \multirow{2}{*}{ Monomer } & \multirow{2}{*}{$\underset{: 0}{\text { Yield, }}$} & \multicolumn{3}{|c|}{ Tacticity, $\%$} & \multirow{2}{*}{ Reference } \\
\hline & & $I$ & $H$ & $S$ & \\
\hline MMA & 35 & 99 & 1 & 0 & 11 \\
\hline BzMA & 8 & 85 & 11 & 4 & 11 \\
\hline (S)-MBMA & 72 & 63 & 17 & 20 & 12 \\
\hline DPMMA & 87 & 25 & 37 & 38 & 1 \\
\hline DMBMA & 87 & 74 & 16 & 10 & This work \\
\hline DPEMA & 83 & 91 & 8 & 1 & 3 \\
\hline TrMA & 0 & - & - & - & 1 \\
\hline
\end{tabular}

ion, ${ }^{13}$ although its exact form is unknown. The stereospecificity in the polymerization of methacrylate by Grignard reagent must be strongly influenced by the steric interaction among the chain end, the incoming monomer and the counter ion. Therefore, the stereospecificity varies largely with the sizes of monomer and Grignard reagent.

\section{Copolymerization of MMA and DMBMA}

In our recent investigation on the copolymerization of various methacrylates with MMA by $n-\mathrm{BuLi}^{3,11,14,15}$ it was found that the relative reactivity of monomers towards MMA anion may be explained in terms of the polar effect of the ester groups, except for the extremely low reactivities of TrMA, DPEMA, and DMBMA in toluene. The monomer reactivity ratios in the copolymerization of MMA and DMBMA were $r_{\mathrm{MMA}}=19.1 \pm 4.0$ and $r_{\mathrm{DMBMA}}=0.56 \pm 0.39$ in toluene, and $r_{\mathrm{MMA}}=2.59 \pm 1.35$ and $r_{\mathrm{DMBMA}}=$ $2.00 \pm 1.10$ in THF.

In the present work it was found that the 
copolymer of MMA and DMBMA obtained in toluene was a mixture of two types of copolymers: one type which consisted mainly of MMA (Part I) and another type which contained both monomers in nearly the same amounts (Part II). Furthermore, the former was a mixture of isotactic and syndiotactic fractions. Similar phenomena were observed in the copolymerizations of MMA-TrMA ${ }^{16}$ and MMA-DPEMA ${ }^{3}$ in toluene.

From these results it should be postulated that in these copolymerizations, there exist three kinds of propagating species: two which preferentially polymerize MMA to the isotactic and syndiotactic polymers, respectively, and the other one which produces a copolymer. The multiplicity of active species has already been proposed in the anionic polymerization and copolymerization of $\alpha$-substituted acrylates. ${ }^{17-23}$

In the highly stereoregulated polymerization of MMA, the rigid conformation of the growingchain end may prevent the incoming of DMBMA and allow the homopolymerization of MMA, while both monomers can copolymerize only in lower stereoregularity. These characteristic features of the copolymerization in toluene are attributed to the large difference between the sizes of MMA and DMBMA.

Part I was produced only in the initial stage of the copolymerization and did not increase thereafter, while the Part II increased with an increase in the polymerization time.

The high molecular weight and small yield of Part I suggest that the active species forming this part exist in a very small concentration but have high reactivity. On the other hand, the low molecular weight of Part II indicates the existence of a higher concentration of active sites and a slow rate of formation of this part. At present it is not certain why Part $I$ is produced only in the initial period. The extremely low reactivity of DMBMA in toluene observed in the monomer reactivity ratios $^{11,13,14}$ can be explained by the formation of Part $I$ in the initial stage of the copolymerization, and therefore, the monomer reactivity ratios, which were obtained from the initial copolymer composition, do not represent the true reactivity ratios of the monomers. The situation may also be the same in the cases of copolymerizations of MMATrMA and MMA-DPEMA in toluene.

In the copolymerization of MMA and DMBMA in THF by $n$-BuLi only the copolymer was obtained that was presumed from the monomer reactivity ratios. The tacticity of the copolymer was nearly equal to that of the homopolymer of DMBMA.

Acknowledgment. The authors are very grateful to Messrs. Kokichi Kanamaru, Kazuo Ohbayashi, and Masayuki Mochida for their help in the laboratory work.

\section{REFERENCES}

1. H. Yuki, K. Hatada, T. Niinomi, and Y. Kikuchi, Polym. J., 1, 36 (1970).

2. H. Yuki, K. Ohta, K. Ono, and S. Murahashi, J. Polym. Sci., Part A-1, 6, 829 (1968).

3. H. Yuki, Y. Okamoto, K. Ohta, Y. Shimada, and K. Hatada, Polymer, 17, 618 (1976).

4. M. Tiffeneau, Ann. Chim., 10, (8) 158 (1907).

5. K. Ziegler and H. G. Gellert, Ann., 567, 179 (1950).

6. K. Hatada, Y. Terawaki, H. Okuda, K. Nagata, and H. Yuki, Anal. Chem., 41, 1518 (1969).

7. S. Murahashi, T. Obokata, H. Yuki, and K. Hatada, Kobunshi Kagaku (Chem. High Polymers), 24, 309 (1967).

8. S. Murahashi, T. Niki, T. Obokata, H. Yuki, and K. Hatada, ibid., 24, 198 (1967).

9. A. Katchalsky and H. Eisenberg, J. Polym. Sci., 6, 145 (1951).

10. H. Inagaki, T. Miyamoto, and F. Kamiyama, ibid., Part B, 7, 329 (1969).

11. H. Yuki, K. Hatada, K. Ohta, and Y. Okamoto, J. Macromol. Sci.-Chem., A9, 983 (1975).

12. H. Yuki, K. Ohta, and T. Kitayama, unpublished data.

13. T. Tsuruta, T. Makimoto, and H. Kanai, $J$. Macromol. Chem., 1, 31 (1966).

14. H. Yuki, Y. Okamoto, K. Ohta, and K. Hatada, Polym. J., 6, 573 (1974).

15. H. Yuki, Y. Okamoto, K. Ohta, and K. Hatada, J. Polym. Sci., Polym. Chem. Ed., 13, 1161 (1975).

16. H. Yuki, K. Hatada, K. Ohta, and Y. Okamoto, unpublished data.

17. H. Yuki, K. Hatada, J. Ohshima, and T. Komatsu, Polym. J., 2, 812 (1971).

18. K. Hatada, J. Ohshima, T. Komatsu, S. Kokan, and H. Yuki, Polymer, 14, 565 (1973).

19. K. Hatada, S. Kokan, and H. Yuki, J. Polym. Sci., Polym. Lett. Ed., 13, 721 (1975). 
H. YUKI, K. Ohta, K. HAtada, and Y. OKamoto

20. K. Hatada, S. Kokan, T. Niinomi, K. Miyaji, and H. Yuki, ibid., 13, 2117 (1975).

21. V. Warzelhan and G. V. Schulz, Makromol. Chem., 177, 2185 (1976).

22. K. Hatada, Y. Umemura, M. Furomoto, S.
Kokan, K. Ohta, and H. Yuki, ibid., 178, 1215 (1977).

23. K. Hatada, Y. Umemura, and $H$. Yuki, Presented at the International Symposium on Macromolecules, Dublin, Ireland, July, 1977. 